\section{ILEGITIMIDADE DO DESCONTO COMPULSÓRIO DA CONTRIBUIÇÃO ASSISTENCIAL NA REMUNERAÇÃO DO FUNCIONÁRIO, SEM PRÉVIA AUTORIZAÇÃO}

\author{
ILLEGITIMACY OF THE COMPULSORY DISCOUNT OF THE \\ ASSISTANCE CONTRIBUTION ON THE EMPLOYEE'S \\ REMUNERATION WITHOUT PRIOR AUTHORIZATION
}

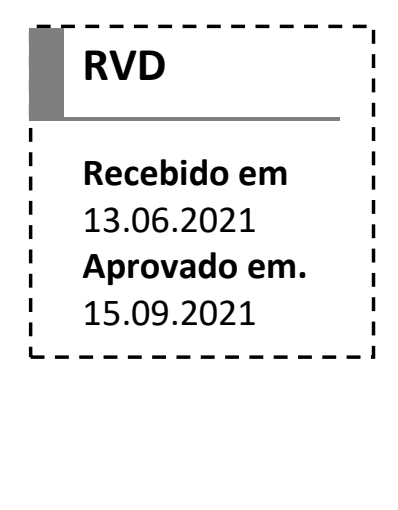

Valdeis Ribeiro da Silva ${ }^{1}$

Maria Leonice S. Berezowski²

\title{
RESUMO
}

A reforma trabalhista de 2017 foi a mudança mais significativa na legislação trabalhista atual, ocasionando mudanças nas relações empregatícias e na justiça do trabalho. Em destaque, a alteração na contribuição sindical que passou a ser opcional, antes era compulsória, ameaçando a fonte de custeio/financiamento da estrutura e de fortalecimento das entidades sindicais. Merece destaque também a informação de que a cobrança da contribuição assistencial foi obrigatória por décadas, o que sempre causou muitas discussões quanto à sua legitimidade. O fato é que durante anos a contribuição assistencial foi deduzida compulsoriamente dos salários dos trabalhadores, independente de autorização prévia, ou até, mesmo independente de serem filiados ao sindicato, tendo como amparo convenção ou acordo coletivo, que suspostamente cumpriria a redação do artigo 513, alínea "e", da CLT. A interpretação equivocada do verbo "impor" do dispositivo jurídico citado ocasionou no desconto compulsório da contribuição, erro que permaneceu por décadas, sendo esta injustiça com os trabalhadores corrigida apenas recentemente. Após inúmeras demandas jurídicas, por meio do julgamento do ARE 1018459, em 2017 houve a decretação da inconstitucionalidade quanto à imposição das contribuições. A imposição da contribuição assistencial ao não associado, ainda que conste em instrumento acordo ou convenção coletiva, fere o princípio da liberdade de associação ao sindicato e também o sistema de proteção ao salário. É salutar informar que à decisão foi atribuída repercussão geral ao tema. Por fim, esta pesquisa foi desenvolvida com

\footnotetext{
${ }^{1}$ Bacharel em Ciências Contábeis pela UFT/TO em 2010, Bacharel em Direito pela UFT/TO em 2015, MBA em Controladoria e Planejamento Tributário pela UFT/TO em 2013, MBA em Contabilidade Pública e Responsabilidade Fiscal pela UNINTER/TO em 2016, Pós-Graduado em Direito Público com Ênfase em Gestão Pública pelo DAMÁSIO/TO em 2016, atualmente empresário Contador e Advogado. E-mail: valdeisilv@gmail.com https://orcid.org/0000-0003-3961-5005

${ }^{2}$ Doutora pela Pontifícia Universidade Católica de Minas Gerais-PUC/MG em 2016, Mestre em Direito pela Universidade de Marília - UNIMAR/SP em 2010, graduada em direito pelo Centro Universitário Filadélfia - UNIFIL/PR em 2006, atualmente professora adjunta da Universidade Federal do Tocantins UFT/TO, Advogada. E-mail: maria.leonice@uft.edu.br https://orcid.org/0000-0001-7002-0558
} 
DOI 10.20873/uft.2359-0106.2021.v8n2.p349-366

abordagem qualitativa, cujo meio metodológico foi o procedimento bibliográfico teóricodocumental.

Palavras-chave: compulsório; contribuição assistencial; inconstitucionalidade; liberdade de associação; repercussão geral.

\section{ABSTRACT}

The 2017 labor reform was the most significant change in the current labor legislation, bringing about changes in employment relations and labor justice. In emphasis, the change in union contribution, which became optional, was previously compulsory, threatening the source of funding/financing of the structure and strengthening of union entities. Also noteworthy is the information that charging the assistance contribution was mandatory for decades, which always caused many discussions as to its legitimacy. The fact is that for years the assistance contribution was compulsorily deducted from the workers' salaries, regardless of prior authorization, or even regardless of being affiliated to the union, based on a convention or collective agreement, which would supposedly comply with the wording of the article 513, subitem "e", of the CLT. The misinterpretation of the verb "impose" in the aforementioned legal provision led to the compulsory discount of the contribution, an error that remained for decades, and this injustice with workers was only recently corrected. After numerous legal demands, through the judgment of ARE 1018459, in 2017 there was a decree of unconstitutionality regarding the imposition of contributions. The imposition of assistance contribution to nonmembers, even if it is contained in an instrument of agreement or collective convention, violates the principle of freedom of association with the union and also the wage protection system. It is healthy to inform that the decision was given general repercussions on the topic. Finally, this research was developed with a qualitative approach, whose methodological means was the theoretical-documentary bibliographic procedure.

Keywords: compulsory; assistance contribution; unconstitutionality; freedom of association; general repercussion.

\section{INTRODUÇÃO}

Recentemente o Brasil sofreu alterações significativas na legislação trabalhista, tendo grande repercussão nas relações empregatícias e na justiça do trabalho, principalmente no que se refere à proteção dos direitos dos trabalhadores.

Dentre os destaques das alterações, trazidas pela Reforma Trabalhista (Lei 13.467 de 2017), tem-se a mudança das regras relativas à remuneração, plano de carreira, jornada de trabalho e uma das alterações mais polêmicas foi referente à contribuição sindical, que a partir da reforma, esta contribuição passou a ser opcional, 
cabendo ao funcionário interessado em contribuir com seu sindicato se manifestar claramente sobre isso.

Esta alteração ocasionou grandes impactos aos sindicatos, comprometendo a viabilidade financeira para exercer sua função precípua de defender os interesses sociais, econômicos e profissionais dos trabalhadores.

Destaca-se que a contribuição sindical, bem como a contribuição assistencial, foi criada com o intuito de financiar ao longo da história a estruturação e fortalecimento das entidades sindicais, pagas por todos os integrantes da categoria, associados ou não ao sindicato.

Neste viés, no tópico 2 do presente artigo, buscar-se-á, a contextualização histórica dos sindicatos, destacando os momentos que marcaram a sua evolução desde a revolução industrial, com o surgimento das sociedades manufatureiras, em países da Europa até o modelo atual, com destaque para as suas fontes de custeios que passaram a constar em texto constitucional e na legislação trabalhista. Dentre elas está a contribuição assistencial que tem amparo no artigo 513, alínea "e", da CLT que é o cerne do estudo deste artigo, pois é eivada de polêmicas relevantes para discussão.

Dito isto, no tópico 3, será possível observar as legislações e entendimentos jurídicos que pairam sobre o tema "contribuição assistencial" e a sua legitimidade ou ilegitimidade, bem como entender a repercussão geral, já que se trata de um tema delicado, pois, diz respeito aos direitos constitucionais como a liberdade de associação e a proteção salarial.

Merece destaque informar que o presente artigo propõe uma discussão teórica que tem como base leituras e pesquisas, com recortes bibliográficos os quais podem ser notados no discorrer dos tópicos a seguir. Destaca-se ainda, a evolução do status da contribuição assistencial, desde a sua instituição até o presente momento, propondo uma discussão a respeito de sua legitimidade/ilegitimidade e postura dos sindicatos frente ao impasse da proteção do salário do trabalhador $x$ contribuição assistencial.

\section{CONTRIBUIÇÃO ASSISTENCIAL E SUA CONTEXTUALIZAÇÃO HISTÓRICA}


Sindicato é uma associação de trabalhadores que tem a função de defender os interesses sociais, econômicos e profissionais. A criação do sindicato ocorre quando um grupo de determinada categoria de trabalhadores se une para defender seus próprios interesses, frente às entidades patronais.

Segundo Dias (2017), a origem do termo Sindicato é do grego "syndike", que significa "protetor", passando a ser usado em países da Europa, após a Revolução Industrial, com o surgimento das sociedades manufatureiras.

$O$ autor frisa ainda que o movimento sindicalista no Brasil começou antes do término da escravidão, na segunda metade do Século XIX, momento em que o escravo estava sendo substituído nas lavouras por trabalhadores assalariados.

Durante o Século XX, com a industrialização no Brasil, os imigrantes, principalmente os italianos, eram atraídos para cá, trazendo consigo a base para o sindicalismo brasileiro, com influência ideológica muito forte. Dito isto, explica a presença do anarquismo, do socialismo e do trabalhismo (ALECRIM, 2018, p. 20).

O mesmo autor aponta em seus estudos que os sindicatos tiveram dificuldade para a formação e aceitação por parte dos governantes, no que tange a proibição, a intolerância, que aos poucos foi evoluindo para a empatia por parte da sociedade dos governos e, por último, o reconhecimento formal com a promulgação de decretos e leis regulamentando $o$ assunto.

Salienta que no início as lutas envolviam reivindicação de melhores condições de trabalho, aumento salarial, jornada de trabalho de oito horas, repouso semanal, regulamentação do trabalho da mulher e do menor.

Com o passar dos anos o sindicato foi ganhando força, por meio de lutas históricas contra as injustiças patronais, ao passo, que também surgiam criações de diversas entidades voltadas para a defesa do trabalhador, eventos, partidos políticos, destacando a criação da Federação Regional do Rio de Janeiro, em 1929 tendo seus efeitos positivos, como se observa: 
A partir de então os sindicatos passaram a se proliferar com o objetivo de defender os direitos trabalhistas dos operários e de seus representantes. Atualmente o Brasil conta com 16.893 sindicatos, sendo 11.606 representantes da classe operária e 5.287 representantes da classe patronal segundo dados do MTE - Ministério do Trabalho e Emprego. (ALECRIM, 2018, p. 19)

No Brasil, os sindicatos abrangem determinada base territorial, podendo ser um município ou até mesmo todo o território nacional, representando determinada categoria. A categoria por sua vez, é o conglomerado de trabalhadores e/ou empregadores que exercem atividade em um mesmo setor da economia. Os trabalhadores pertencem a uma categoria profissional, enquanto os empregadores pertencem a uma categoria econômica (ALECRIM, 2018).

A categoria econômica é definida em razão da atividade preponderante da empresa (art. 511, § 1, CLT) e a categoria profissional, por sua vez, é definida em razão do trabalho do empregado em favor da empresa de determinada categoria econômica (art. 511, § 2o, CLT), com exceção de categoria profissional que exercem profissões diferentes por força de estatuto profissional, ou em consequência de condições de vida singulares (art. $511, \S \S 2^{\circ}$ e $3^{\circ}$, da CLT).

Pode-se citar como exemplos de categoria profissional, que representam os trabalhadores empregados, os comerciários, pois existe sindicato dos trabalhadores no comércio (sindicato laboral) e, como exemplo da categoria econômica, tem-se o setor do comércio, pois existe o sindicato dos comerciários (sindicato patronal).

Assim, o enquadramento sindical do empregado será determinado pela atividade preponderante da sociedade empresária, entendendo-se como tal a que caracterizar o carro chefe de suas atividades, maior fonte de receita, operação ou objetivo final, para cuja obtenção todas as demais atividades convirjam, exclusivamente, em regime de conexão funcional (art. 581, $2^{\circ}$, da CLT), faz-se necessário o enquadramento, pelo fato de definir a qual sindicato o empregador poderá filiar-se, e realizar o pagamento das contribuições de fontes de custeio sindical.

Como fonte de custeio, os sindicatos têm as receitas ordinárias e as receitas extraordinárias (como por exemplo, doações, legados, multas, sorteios, rifas etc.), esta última prevista no art. 548 da CLT: 
Art. 548 - Constituem o patrimônio das associações sindicais:

(...)

c) os bens e valores adquiridos e as rendas produzidas pelos mesmos;

d) as doações e legados;

e) as multas e outras rendas eventuais.

Stürmer (2020, p. 5) informa que as quatro fontes oficiais de custeio do sindicato (receitas ordinárias), são, a contribuição sindical, a contribuição confederativa, a contribuição associativa e a contribuição assistencial. Existem também formas de arrecadação dos sindicatos, porém consideradas oficiais, entretanto no presente estudo serão abordadas apenas a contribuição sindical e a contribuição assistencial.

A contribuição sindical foi instituída, ainda na Constituição de 1937, com a finalidade de oferecer receita aos sindicatos para custeio de suas atividades de caráter compulsório, aqui denominada de imposto sindical e mais tarde (1966), por meio do Decreto-lei 27, a denominação passou a ser contribuição sindical, mantida até hoje (arts. 578 a 610 da CLT).

Com a aprovação da Lei Federal 13.467/2017, o que se observou foi uma drástica alteração com relação à natureza tributária da contribuição sindical, deixando esta de ser compulsória e passou a ser facultativa. A mencionada "Reforma Trabalhista" modificou substancialmente os direitos trabalhistas, no aspecto individual, coletivo e processual.

A Contribuição confederativa é mais recente, comparando-a com as demais, tem previsão legal na Constituição Federal em seu art. 8º, IV:

\footnotetext{
"É livre a associação profissional ou sindical, observado o seguinte:(...) IV - a assembleia geral fixará a contribuição que, em se tratando de categoria profissional, será descontada em folha, para custeio do sistema confederativo da representação sindical respectiva, independentemente da contribuição prevista em lei".
}

Esta contribuição é prevista apenas para a categoria profissional e não para a categoria econômica e apesar de ser prevista constitucionalmente, pode ser criada somente mediante assembleia geral do sindicato, com o intuito de custear o sistema confederativo. 
De acordo com Stürmer (2020, p.16), conforme citado por Martins, "a contribuição confederativa é a prestação pecuniária, espontânea, fixada pela assembleia geral do sindicato, tendo por finalidade custear o sistema confederativo".

A Contribuição associativa pode ser imposta por meio de previsão no estatuto da entidade sindical, uma vez que tem natureza de associação, com previsão no art. 548, alínea "b", da CLT.

Esta contribuição é fixada pelos próprios interessados e cobrada em razão dos benefícios prestados pela entidade sindical aos seus associados, portanto, é a única contribuição que não é polêmica, bem como, que se insere nos limites e padrões da verdadeira liberdade sindical (STÜRMER, 2020, p.17).

Já a contribuição assistencial criada por meio de convenção ou acordo coletivo será paga mediante desconto em folha do sindicalizado, em uma ou mais parcelas, durante o exercício, com intuito de custear despesas para manutenção do ente sindical, na luta por melhorias nos interesses representados, conforme estabelecido na CLT, artigo 513, alínea "e" combinado com o inciso IV do artigo 8 da CF (CASTRO, DELBEN e FERREIRA, 2019, p. 171).

De acordo com Coelho e Albuquerque (2017, p.29) a contribuição assistencial tem como fundamento jurídico a norma coletiva, trata-se de valor pago pelo empregado, desde que seja associado ao sindicato que o representa, respeitando o princípio da livre associação sindical.

Diferente do que aponta os autores acima, a contribuição assistencial, ao longo das décadas foi cobrada automaticamente dos empregados, por seus empregadores, uma vez, que se viram reféns das convenções e acordos trabalhistas que previam o desconto compulsório dos salários dos obreiros, com o conseguinte repasse dos valores aos cofres do sindicato da categoria. Caso as empresas se opusessem sofreriam as sanções previstas também na norma coletiva.

Desse modo é o que se pretende demonstrar no tópico seguinte com observação aos desdobramentos dessa contribuição na justiça do trabalho. 


\section{A CONTRIBUIÇÃO ASSISTENCIAL E SEUS DESDOBRAMENTOS NA JUSTIÇA DO TRABALHO}

A contribuição assistencial tem amparo no artigo 513, alínea "e", da CLT, o que traz o seguinte enunciado: "Art. 513. São prerrogativas dos sindicatos: e) impor contribuições a todos àqueles que participam das categorias econômicas ou profissionais ou das profissões liberais representadas".

Desde a sua instituição, é uma contribuição polêmica quanto ao seu desconto ser compulsório ou não, independentemente do trabalhador ser associado à entidade sindical.

Segundo Neto e Santos (2019, p. 128) na década de 70, o STF admitiu o desconto da contribuição assistencial aos que estivessem associados ao sindicato, no entanto, o direito de se opor deveria ser assegurado. Tem-se:

SENTENÇA NORMATIVA EM DISSÍDIO COLETIVO. [...] NÃO CONTRARIA A CONSTITUIÇÃO CLÁUSULA, EM DISSÍDIO COLETIVO, DE DESCONTO, A FAVOR DO SINDICATO, NA FOLHA DE PAGAMENTO DOS EMPREGADOS, DE PERCENTAGEM DO AUMENTO REFERENTE AO PRIMEIRO MÊS, DESDE QUE NÃO HAJA OPOSIÇÃO DO EMPREGADO ATÉ CERTO PRAZO ANTES DESSE PAGAMENTO. - [...] (STF - RE: 88022 SP, Relator: Min. MOREIRA ALVES, Data de Julgamento: 16/11/1977, Tribunal Pleno, Data de Publicação: DJ 10-03-1978 PP-01176 EMENT VOL-01087-02 PP-00781 RTJ VOL-00086-03 PP-00897) (NETO e SANTOS, 2019, p. 128)

Da decisão acima, percebe-se que o desconto deveria ser lançado na folha de pagamento automaticamente, sendo necessário o comparecimento do trabalhador ao sindicato para requerer por escrito a suspensão das cobranças.

Ocorre que a Constituição Federal de 1988, alterou o regime sindical brasileiro, extinguindo o estado opressor e consagrando o novo sistema de liberdade sindical. A Carta Magna, em seu artigo $8^{\circ} \mathrm{e}$ incisos, em especial o $\mathrm{V}$, que expressa: "ninguém será obrigado a filiar-se ou a manter-se filiado a sindicato", não se admite a sindicalização forçada.

Ao longo de décadas houve diversas tentativas de regularizar a contribuição assistencial. Destaca-se que em 2009, o Ministro do Trabalho Carlos Lupi editou a Ordem de Serviço no 01, autorizando a cobrança da contribuição dos não associados, 
DOI 10.20873/uft.2359-0106.2021.v8n2.p349-366

desde que aprovada em assembleia geral, com participação maciça da categoria, previsão na convenção ou acordo coletivo e assegurado o direito de oposição dos não associados.

Destaca-se ainda, que houve a tentativa de conciliar a contribuição assistencial e o princípio da liberdade sindical. É sabido que o STF já havia se posicionado de forma semelhante RE 220.700 RS, julgado em 06/10/1998 (NETO e SANTOS, 2019, p. 128).

No mesmo sentido o TST, regulou o direito de oposição por meio do Precedente Normativo n. 74, cancelado em 1998, passando a ter um entendimento mais taxativo, no mesmo ano, editando o Precedente n. 119 que enfatizou a nulidade das cláusulas de convenções e acordos coletivos que obrigam o pagamento de contribuições a qualquer título por trabalhadores não associados.

№ 119 CONTRIBUIÇÕES SINDICAIS - INOBSERVÂNCIA DE PRECEITOS CONSTITUCIONAIS - (mantido) - DEJT divulgado em 25.08.2014 "A Constituição da República, em seus arts. 5, XX e 8ํㅡ, V, assegura o direito de livre associação e sindicalização. É ofensiva a essa modalidade de liberdade cláusula constante de acordo, convenção coletiva ou sentença normativa estabelecendo contribuição em favor de entidade sindical a título de taxa para custeio do sistema confederativo, assistencial, revigoramento ou fortalecimento sindical e outras da mesma espécie, obrigando trabalhadores não sindicalizados. Sendo nulas as estipulações que inobservem tal restrição, tornam-se passíveis de devolução os valores irregularmente descontados."

Corroborando com a Orientação Jurisprudencial do TST no 17 de 1998, que ainda reiterou a possibilidade de devolução dos descontos efetuados aos não associados (NETO e SANTOS, 2019, p. 130).

17. CONTRIBUIÇÕES PARA ENTIDADES SINDICAIS. INCONSTITUCIONALIDADE DE SUA EXTENSÃO A NÃO ASSOCIADOS. (mantida) - DEJT divulgado em 25.08.2014 As cláusulas coletivas que estabeleçam contribuição em favor de entidade sindical, a qualquer título, obrigando trabalhadores não sindicalizados, são ofensivas ao direito de livre associação e sindicalização, constitucionalmente assegurado, e, portanto, nulas, sendo passíveis de devolução, por via própria, os respectivos valores eventualmente descontados.

É importante citar, ainda, que a Súmula 666 do STF, que foi convertida em Súmula vinculante no 40, com a seguinte redação "A contribuição confederativa de que trata 0 art. 8ํ, IV, da Constituição Federal, só é exigível dos filiados ao sindicato 
respectivo." cuida da contribuição confederativa, entendimentos esses que por analogia também são aplicados à contribuição assistencial.

Salienta-se que em recurso à decisão proferida pelo STF no RE 220.700, é sustentada a interpretação que o desconto da contribuição assistencial aos não filiados deve ocorrer, sob o argumento de que a falta de cobrança desestimularia a sindicalização, já que, filiado ou não gozaria do êxito das lutas do sindicato em razão da categoria. (NETO e SANTOS, 2019, p. 131)

Em que pese, para Coelho e Albuquerque (2017, p. 33), ocorreram mudanças de posicionamentos dos tribunais superiores, especialmente junto ao Supremo Tribunal Federal e ao Tribunal Superior do Trabalho.

Tão logo à questão foi atribuída a repercussão geral, e em decisão recente o STF considerou a inconstitucionalidade da obrigatoriedade do desconto da contribuição assistencial dos trabalhadores não sindicalizados, observa-se a ementa:

Recurso Extraordinário. Repercussão Geral. 2. Acordos e convenções coletivas de trabalho. Imposição de contribuições assistenciais compulsórias descontadas de empregados não filiados ao sindicato respectivo. Impossibilidade. Natureza não tributária da contribuição. Violação ao princípio da legalidade tributária. Precedentes. 3. Recurso extraordinário não provido. Reafirmação de jurisprudência da Corte. (ARE 1018459 RG, Relator (a): Min. GILMAR MENDES, julgado em 23/02/2017, PROCESSO ELETRÔNICO REPERCUSSÃO GERAL - MÉRITO DJe-046 DIVULG 09-03-2017 PUBLIC 1003-2017)

(STF - RG ARE: 1018459 PR - PARANÁ, Relator: Min. GILMAR MENDES, Data de Julgamento: 23/02/2017, Tribunal Pleno - meio eletrônico, Data de Publicação: DJe-046 10-03-2017)

A interpretação que se faz do enunciado trazido acima é de que, a contribuição assistencial não possui natureza tributária, sendo assim, as normas coletivas jamais poderiam impor a sua cobrança, visto que, prever sua obrigatoriedade aos trabalhadores não sindicalizados é inconstitucional, e ainda, ofende diretamente o princípio constitucional da liberdade de associação, que será tratada no tópico seguinte.

\section{A DECLARAÇÃO DE INCONSTITUCIONALIDADE DA CONTRIBUIÇÃO ASSISTENCIAL E SUA EFETIVA ABRANGÊNCIA}


É salutar informar que em 2009, o STF rejeitou o acolhimento da repercussão geral acerca do tema, o Relator e Ministro na ocasião, Cezar Peluso, justificou que se tratava de matéria infraconstitucional, utilizando como fundamento, precedentes da Corte, no Agravo de Instrumento 752.633, interposto em face de decisão que indeferiu o Recurso Extraordinário do Sindicato em questão, que buscava o reconhecimento da repercussão geral sobre o tempo (BRANCO, 2017, p. 125).

Sabe-se que em 2017 o ARE 1018459, tendo como Relator o Ministro Gilmar Mendes e como partes o Sindicato dos Trabalhadores nas Indústrias Metalúrgicas, de Máquinas, Mecânicas, de Material Elétrico, de Veículos Automotores, de Autopeças e de Componentes e Partes para Veículos Automotores da Grande Curitiba (SMC) e o MPT, onde o Ministério Público do Trabalho sustenta a inconstitucionalidade do desconto compulsório, visto que retira a obrigatoriedade do repasse pelos não associados da contribuição assistencial, com fulcro no Precedente 119 do TST, um entendimento que foi confirmado pelo STF, em março de 2017.

Tem-se:

Tese: É inconstitucional a instituição, por acordo, convenção coletiva ou sentença normativa, de contribuições que se imponham compulsoriamente a empregados da categoria não sindicalizados. Tema: 935 - Inconstitucionalidade da contribuição assistencial imposta aos empregados não filiados ao sindicato, por acordo, convenção coletiva de trabalho ou sentença.

Do inteiro teor da decisão é possível extrair que foi atribuída a repercussão geral ao tema, conforme mencionado no item anterior, e informou que com exceção à contribuição sindical, a imposição de cobrança/pagamento de qualquer outra contribuição a não associado, ainda que conste em instrumento acordo ou convenção coletiva, fere o princípio da liberdade de associação ao sindicato e também o sistema de proteção ao salário.

A decisão considerou ofensiva a modalidade de liberdade de cláusula que fixa contribuição em favor da entidade sindical sob o argumento que servirá para custeio e fortalecimento, almejando conquistas para a categoria, obrigando os trabalhadores não sindicalizados a sofrerem a retenção em seus salários. 
DOI 10.20873/uft.2359-0106.2021.v8n2.p349-366

Considerando a decisão em seu inteiro teor, onde, ainda que houvesse necessidade de direito a oposição do desconto da contribuição, não faria sentido o desconto ser automático de trabalhador não associado e cessar apenas com a manifestação do mesmo. Observe o trecho que justifica a repercussão geral do tema:

\begin{abstract}
Assim, a questão ora posta reside em saber se é compatível com a Constituição a imposição de contribuição compulsória, por meio de acordo ou convenção coletiva de trabalho, a empregados não filiados ao sindicato respectivo. Essa discussão é de inegável relevância dos pontos de vista jurídico, econômico e social, na medida em que fixa tese potencialmente direcionada a todos os empregados não filiados a sindicatos, tendo reflexo também na organização do sistema sindical brasileiro e na sua forma de custeio. Portanto, o conflito não se limita aos interesses jurídicos das partes recorrentes, razão pela qual a repercussão geral da matéria deve ser reconhecida.
\end{abstract}

Depreende-se do trecho da decisão, que a mesma teve alcance geral. Tem-se como reflexo da decisão a nulidade das convenções que impuseram a compulsoriedade do pagamento de contribuição assistencial dos não filiados à entidade, sendo nulas essas estipulações, já que não observaram a restrição, abrindo assim o precedente para restituição/devolução dos eventualmente descontados.

Tem-se por fim a interpretação correta do art. 513 da CLT, visto que a imposição da contribuição assistencial deve ser direcionada somente à "aqueles que participam das categorias econômicas ou profissionais ou das profissões liberais representadas".

Também existe a possibilidade dos trabalhadores não associados contribuírem, desde que autorizem a cobrança, independentemente de associar-se. De toda forma, a fim de ratificar tal informação, observe o enunciado do Art. 545 da CLT:

Os empregadores ficam obrigados a descontar da folha de pagamento dos seus empregados, desde que por eles devidamente autorizados, as contribuições devidas ao sindicato, quando por este notificados.

É imperioso estar atento a todos os fatores relacionados à contribuição assistencial, inclusive em decorrência da Reforma Trabalhista. Observe o enunciado do Art. 611 B, XXVI , trazido pela Lei 13467/17:

Art. 611-B. Constituem objeto ilícito de convenção coletiva ou de acordo coletivo de trabalho, exclusivamente, a supressão ou a redução dos seguintes direitos:

(...) 
XXVI - liberdade de associação profissional ou sindical do trabalhador, inclusive o direito de não sofrer, sem sua expressa e prévia anuência, qualquer cobrança ou desconto salarial estabelecidos em convenção coletiva ou acordo coletivo de trabalho;

É importante ressaltar que a autorização de desconto da contribuição assistencial deve ser formalizada por escrito, informando à empresa e ao sindicato em que o trabalhador está associado.

O entendimento resguarda e protege o trabalhador, em especial o salário, mantendo a sua capacidade de sobrevivência e o direito à dignidade humana, mesmo que decorrentes de contribuições da entidade sindical (COELHO e ALBUQUERQUE, 2017, p. 36).

É sabido que obrigatória ou não a autorização para o desconto da contribuição assistencial ou de qualquer desconto na folha de pagamento gera dúvidas. Neste viés é conveniente o empregador por meio do seu Departamento de Recursos - $\mathrm{RH}$ prestar esclarecimentos ou dar orientações aos obreiros.

Não é de se estranhar que o empregador desconheça ou se equivoque quanto ao desconto realizado. Assim, é possível que o empregador deixe de descontar a contribuição assistencial do empregado devidamente filiado e descontar do não filiado. Com isso, torna-se imperioso os esclarecimentos ao funcionário para possíveis alinhamentos, a fim de evitar erros e transtornos com relação a este tema.

De acordo com Branco (2017, p. 8) torna-se evidente as consequências jurídicas que os sindicatos terão caso não adotem o rigor da lei, caso deixem de observar atentamente a autorização expressa do empregado para que 0 desconto da contribuição assistencial ocorra, observe:

Diante do exposto, os sindicatos devem respeitar o arquétipo jurídico que prevê as formas de receitas possíveis para seu custeio, a fim de preservar os direitos dos trabalhadores que se encontram inseridos nas respectivas categorias profissionais ou econômicas, estejam eles filiados ou não, sob a consequência de enfrentarem demorados e custosos processos, inclusive ações públicas manejadas pelo Ministério Público do Trabalho.

Esta é a mensagem primordial que pôde ser extraída do estudo realizado neste escrito, cuja jurisprudência encontra-se agora duplamente consolidada no Supremo Tribunal Federal. (grifo nosso) 
DOI 10.20873/uft.2359-0106.2021.v8n2.p349-366

Diante do exposto e ainda que haja falta de acesso à informação por parte de grande parte dos obreiros no Brasil, é considerável o volume de ações que buscam a devolução dos valores retidos sem autorização prévia, mediante Acordo ou Convenção Coletiva, observe:

DEVOLUÇÃO DA CONTRIBUIÇÃO ASSISTENCIAL. Consoante ditado pela sentença, não há qualquer autorização por parte do reclamante para os descontos efetuados em seu salário. As contribuições, assistencial e/ou confederativa, apenas podem ser descontadas dos filiados ao sindicato, sob pena de ofensa ao princípio constitucional da liberdade de associação. Nesse sentido são a Súmula 666 do STF e o Precedente Normativo 119 da SDC do TST. Assim sendo, mantenho a sentença que determinou o reembolso dos descontos salariais realizados sob o título de contribuição assistencial e confederativa. Não há como se estender a exigência de descontos a título de contribuição assistencial, ou mesmo confederativa aos empregados não filiados ao Sindicato, eis que não obstante a autorização em assembleia geral, a cobrança é ofensiva a liberdade de associação e de sindicalização (arts. 5, XX e $8^{\circ}, \mathrm{V}$ da CF/88). Não havendo prova nos autos de que o reclamante seja filiado ao sindicato, mantenho a sentença. Nego Provimento. (TRT-2 10014162620195020038 SP, Relator: IVANI CONTINI BRAMANTE, 4" - Turma - Cadeira 5, Data de Publicação: 18/11/2020) (grifo nosso)

EMENTA: PROCESSO SELETIVO. TREINAMENTO. VÍNCULO ANTERIOR. O contexto dos autos denotou que no período de treinamento promovido pela reclamada houve efetiva capacitação, com cumprimento de horário regular pela parte reclamante, além de subordinação, configurando o vínculo anterior. INDENIZAÇÃO POR DANOS MORAIS. CONTROLE EXCESSIVO NAS PAUSAS PARA IR AO BANHEIRO. O foco na produtividade não pode perder de vista a dignidade da pessoa humana e a proteção à saúde do trabalhador. Constatada a imposição de limitações desarrazoadas por parte do empregador ao direito do empregado em deixar o posto de serviço para ir ao banheiro, temse por configurado o dano moral. DESCONTO DE EMPREGADOS NÃO SINDICALIZADOS. DIREITO DE OPOSIÇÃO. ILEGALIDADE. Este Regional vem considerando inválida a contribuição endereçada a empregados não sindicalizados (Precedente Normativo no 119 do TST), mesmo quando constar do instrumento coletivo a possibilidade de oposição do empregado ao desconto, como no caso dos presentes autos. Além disso, o excelso STF converteu a sua súmula 666 na súmula vinculante 40 , que estabelece que "A contribuição confederativa de que trata o art. 8ㅇ, IV, da Constituição Federal, só é exigível dos filiados ao sindicato respectivo". Logo, correta a sentença que determinou a devolução da contribuição assistencial cobrada do empregado não sindicalizado. Recurso conhecido e não provido.

(TRT-10 - RO: 00025771320165100801 DF, Data de Julgamento: 11/12/2019, Data de Publicação: 19/12/2019) (grifo nosso) 
Uma vez sendo exercido o direito constitucional de não filiar-se, o não associado não está obrigado a honrar os compromissos previstos em estatuto/convenção, consequentemente não deverá pagar contribuições adotadas em assembleias que sequer compareceu. (MELO, 1995, p. 67)

Ainda conforme Melo (1995, p. 63), é sabido que os sindicatos permaneceram por várias décadas vivendo em penúria, sendo que a partir da década de 60 , com a instituição da contribuição assistencial, possibilitou-se a reestruturação das entidades sindicais. Assim, por anos os sindicatos continuaram a efetuar o desconto, até a decisão (2017) que declarou inconstitucional sua compulsoriedade.

Diante de tal cenário, o que se pode evidenciar é a urgência necessária de mudança de postura das associações sindicais, as quais devem se manter com seus recursos providos pelos seus associados de forma voluntária, contribuindo assim para a existência e permanência da verdadeira e legítima representação sindical.

\section{CONSIDERAÇÕES FINAIS}

Diante dos argumentos apresentados é cediço pontuar que ao longo das décadas os sindicatos, no Brasil e no mundo, ganharam força e cada vez mais representatividade coletiva.

No Brasil, como principal fonte de financiamento da atividade sindical está a contribuição assistencial, objeto deste estudo, a princípio paga por qualquer trabalhador de determinada categoria, independentemente de ser associado ou não, sendo descontada compulsoriamente dos salários dos obreiros.

Conclui-se que a contribuição assistencial não tem natureza tributária e por este motivo não pode ser imposta.

Deduzir a contribuição assistencial de forma obrigatória dos salários dos trabalhadores não associados é inconstitucional, além de ofender o princípio constitucional da liberdade de associação e da proteção salarial.

Do inteiro teor da decisão do ARE 1018459, incidente de repercussão geral, tendo como Relator o Ministro Gilmar Mendes, concluiu-se que obrigar o trabalhador 
que não é associado a pagar de contribuição assistencial ao sindicato que representa a sua categoria profissional, configura a mais ampla e plena inconstitucionalidade, ferindo o princípio da liberdade de associação ao sindicato e também ao sistema de proteção ao salário.

Como não há fundamento expresso, lícito, que exija o pagamento da contribuição assistencial, é plausível demandar judicialmente para reparação dos danos materiais ocasionados aos trabalhadores que tiveram as deduções indevidas de seus proventos, desde que não haja autorização expressa para o desconto efetuado em seu salário.

Por fim, conclui-se que, a mudança no entendimento da Justiça do Trabalho, deixa transparecer que a cobrança de contribuição assistencial compulsoriamente, sem autorização expressa do trabalhador, é inconstitucional, cabendo aos sindicatos se adequarem e a partir das contribuições voluntárias dos associados, ou seja, Um Sindicato verdadeiro e legítimo a serviço do trabalhador.

\section{REFERÊNCIAS}

ALECRIM, Luis Carlos Rodrigues. Financiamento Sindical e seus Novos Desafios Pósreforma Trabalhista. São Paulo, 2018.

BRANCO, Heitor Kulig. "Contribuições Sindicais" X "Contribuições Assistenciais": Análise Jurisprudencial e Delimitação De Conceitos. Revista do Curso de Direito da Faculdade de Humanidades e Direito, v. 14, n. 14, 2017.

COELHO, Bernardo Leôncio Moura; ALBUQUERQUE, Edmilson Dias de. Dos limites à contribuição sindical assistencial: novos posicionamentos do STF e do TST. Rev. do Trib. Reg. Trab. 10ª Região, Brasília, v. 21, n. 1, 2017.

\footnotetext{
$\begin{array}{llll}\text {. Constituição da República Federativa do Brasil de 1988. Brasília, } 5 \text { de } \\ \text { outubro } & 1988 . & \text { Disponível } & \text { em: }\end{array}$ <http://www.planalto.gov.br/ccivil_03/constituicao/constituicao.htm>. Acesso em $03 \mathrm{dez}$. 2020.
} 
CRASTO, Alexandre Augusto Zaghini; DELBEN, Ana Cleusa; FERREIRA, Paulo Henrique de Campos Lopes. Receita Sindical: Impactos da reforma trabalhista. Revista TST, São Paulo, vol. 85, n 1, jan/mar 2019.

. Decreto-Lei oㅜ 5.452, de $1^{\circ}$ de maio de 1943. Aprova a Consolidação das Leis do Trabalho. Disponível em: <http://www.planalto.gov.br/ccivil_03/decretolei/del5452.htm>. Acesso em: 28 fev. 2021.

DIAS, Antônio Carlos. A história das organizações sindicais. 2004. Disponível em: <http://www.arcos.org.br/artigos/a-historia-das-organizacoes-sindicais/>. Acessado em: 02 dez. 2020.

. Lei no 13.467, de 13 de julho de 2017. Altera a Consolidação das Leis do Trabalho (CLT). Disponível em: <http://www.planalto.gov.br/ccivil_03/_ato20152018/2017/lei/l13467.htm>. Acesso em: 28 fev. 2021.

MELO, Raimundo Simão de. A Contribuição Assistencial Sindical sob a Nova Ótica do Ministério Público do Trabalho e do Judiciário. JusLaboris, 1995. Disponível em: <https://juslaboris.tst.jus.br/bitstream/handle/20.500.12178/111916/1995_melo_raimund o_contribuicao_assistencial.pdf?sequence=1\&isAllowed=y >. Acesso em: $28 \mathrm{fev} .2021$.

NETO, Alberto Emiliano de Oliveira; SANTOS, Enoque Ribeiro dos. Reforma Trabalhista e Financiamento Sindical. Contribuição Assistencial/Negocial dos Não-Filiados. JusLaboris, 2018. Disponível em: $<$ https://juslaboris.tst.jus.br/bitstream/handle/20.500.12178/152271/2019_oliveira_neto_ alberto_reforma_trabalhista.pdf?sequence=1\&isAllowed=y>. Acesso em: 28 fev. 2021.

STÜRMER, Gilberto, André Luiz. Contribuições Sindicais. Enciclopédia Jurídica da PUCSP, Direito do Trabalho e Processo do Trabalho. São Paulo, 2020.

. Supremo Tribunal Federal. ARE: 1018459 PR - PARANÁ. Relator: Min. GILMAR MENDES, Data de Julgamento: 23/02/2017, Tribunal Pleno - meio eletrônico, Data de Publicação: DJe-046 10-03-2017. Disponível em: < https://redir.stf.jus.br/paginadorpub/paginador.jsp?docTP=TP\&doclD=12540767>. Acesso em: 02 dez. 2020.

. Supremo Tribunal Federal. Súmula Vinculante 40. A Súmula Vinculante 40 resultou da conversão da Súmula 666. DJE de 20-3-2015. Disponível em: http://www.stf.jus.br/portal/jurisprudencia/menuSumario.asp?sumula=2204>. Acesso em: 02 dez. 2020.

- Tribunal Superior do Trabalho. Precedente 119 Contribuições Sindicais Inobservância de Preceitos Constitucionais - (mantido) - DEJT divulgado em 25.08.2014. 


\section{Vertentes do Direito}

ISSN no 2359-0106

Vol. 8, n. 2, 2021.

DOI 10.20873/uft.2359-0106.2021.v8n2.p349-366

<https://www3.tst.jus.br/jurisprudencia/PN_com_indice/PN_completo.html\#Tema_PN11 9>. Acesso em: 28 fev. 2021. 